\title{
Synthesis and Evaluation of Multifunction Co-Polymer as Lubricating Oils Additives
}

\section{Al-Shafey HI* and Arafa EI}

Egyptian Petroleum Research Institute, Nasr city, Cairo, Egypt

*Corresponding author: Hussin Al-Shafey, Egyptian Petroleum Research Institute, Nasr city, Cairo, Egypt, Tel: +2 01126844581; Email: mhussin14@yahoo.com

\section{Research Article}

Volume 2 Issue 4

Received Date: May 25, 2018

Published Date: June 08, 2018

\section{Abstract}

$\alpha$ - Olefin derivatives are one of a variety of techniques have been employed in order to reduce problems caused by the crystallization of paraffin during the production and/or transportation and improved of properties of petroleum oils and derivatives. Addition of chemical modifications has been proved to be an efficient way for improving properties of lube oils. This article describes synthesis, characterization and performance evaluation of copolymers, having as an initial step the synthesis of the alkyl methacrylate monomers by esterification of methacrylic acid (MA) with $\mathrm{C}_{16}$ fatty alcohol. The alkyl methacrylate monomer was polymerized with $\alpha$ - olefin $\mathrm{C}_{16}$ (1-Hexadecene) to give copolymer then reacted with vinyl acetate monomer to give finally graft copolymer. The prepared graft copolymer was characterized by FT-IR, ${ }^{1} \mathrm{HNMR}$ spectroscopy, and gel permeation chromatography (GPC), and use to improving the properties of different types (high and low viscositys) of Egyptian lubricating oils. Lubricating oils with different concentrations of graft copolymer (1000, 3000, 5000 and 10000 ppm) were investigated by pour point depressant (PPD), viscosity index (VI) and rheological measurements (RM). The lubricants formulated with chemically modified exhibit a large reduction in the pour point temperatures, good rheological behaviors and better friction and wear properties. Oil samples containing $5000 \mathrm{ppm}$ of the graft copolymer show $-18^{\circ} \mathrm{C}$ reductions in their pour points and give good performances properties for this lube oils, thus establishing the large efficiency of the products synthesized in this work.

Keywords: Pour point depressants; Flow improvers; Fatty acid; Lubricating oil; Rheological properties

\section{Introduction}

Lubricating oils containing predominantly paraffin materials, the less soluble components of which start separating out at the low temperature as small crystals. The temperature at which this phenomenon occurs is known as cloud point. Further cooling results in the formation of a rigid interlocked crystal lattice trapped in to the liquid hydrocarbon materials and prevents the flow of the oil [1]. One of the essential requirements of engine lubricating oil is that it must have a low enough viscosity at low temperatures to assist in cold starting and a high enough viscosity at high temperatures to maintain its load bearing characteristics. It is therefore desirable to have a fluid whose viscosity-temperature dependence is small $[2$, 3]. 


\section{Petroleum \& Petrochemical Engineering Journal}

The lowest temperature at which the oil can still flow is termed pour point. If the pour point is not below the desired temperature, problems are encountered during storage and in actual usage of the lubricant [1]. To improve the quality, lube oil always contains different types of additives or additives are mixed to the lube oil to impart a new and desirable property which was not originally present in the oil. Sometimes additives amplify the property already present to some degree in the oil [4$6]$.

Types of additives are antioxidants, detergents and dispersants, corrosion inhibitors, viscosity index improvers (VIIs) and pour point depressants (PPDs), etc. Of them VIIs and PPDs are the very important ingredients in modern lubricants.

PPDs are chemical additives which are used to transport lube oils at low-temperature areas. They are added to maintain oil flow ability below a certain temperature which is termed as pour point (PP) and defined as the temperature at which the flow ability of oil totally ceases due to wax crystal lattice formation [7]. These are basically polymeric compounds made of hydrocarbon chains. At the time when the temperature becomes low and the oil cools down, then during the development of wax crystal network, the hydrocarbon chains become inserted in the lattice and thus inhibit wax crystal formation or modify the wax crystal network. So they are also known as wax crystal modifiers. Among the different kinds of polymers, acrylic and methacrylic ester polymers are very efficient as crude oil wax crystal modifiers and wax deposition inhibitors [8-11]. Again, viscosity is a very important property of a lubricant [12]. The viscosity of a liquid is a measure of its resistance to flow.

High viscosity oil is less fluid than the one of low viscosity. At higher temperatures, the oil tends to thin out and flow more readily and vice versa. The change in viscosity with the variation of temperature is expressed by a parameter known as viscosity index (VI). Higher VI of oil means the viscosity of the oil does not vary much with the variation of temperature [13]. VIIs or viscosity modifiers (VMs) are added to the lubricating oil to improve the VI of the oil $[14,15]$.

This study was motivated by the need for a greater understanding of the characteristics of the polymers used as viscosity index improvers in lubricating oil, rheological properties and pour point depressant. This study included the determination of the kinematic viscosity of the mixtures, the calculation of the viscosity indexes and their behavior when subjected to various rheometric tests. So, to find out efficient multifunction for lubricating oils, a hetero atom containing polymers (graft copolymer) was prepared and characterized, and the influence of the structure of the graft copolymer as pour point depressant and viscosity index improvers were mainly investigated in this paper.

\section{Experimental}

\section{Materials}

Methacrylic acid (MAA), 1-Decanol (DA), Vinyl acetate (VA), $\alpha$ - olefin $\mathrm{C}_{16}$ (1-Hexadecene), P-Toluene sulfunic acid monohydrate (PTSA), Benzyl peroxide (BzPO) from Aldrich Chemicals. Two Egyptian lubricating oils, one of light viscosity and other of high viscosity lubricating oils were used for this study.

\section{Synthesis of MAA-DA Ester}

MAA-DA ester was prepared by reacting of Methacrylic acid $(0.1 \mathrm{~mol})$ with Decyl alcohol $(0.11 \mathrm{~mol})$ under $\mathrm{N}_{2}$ gas at $110{ }^{\circ} \mathrm{C}$ in toluene in the presence of $1 \%$ PTSA (wt \% based on total weight of reactants). The reaction was carried out in a four-neck flask glass equipped with a stirrer, thermometer, nitrogen gas inlet and a reflux condenser. The water of the esterification reaction was removed throughout the course of the reaction using Dean and Stark separator. The MAA monomer was first dissolved in toluene, and then PTSA catalyst and DA were added to reaction medium the increase temperature gradual into $110^{\circ} \mathrm{C}$ for $6 \mathrm{~h}$.

\section{Synthesis of MAA-DA- $\alpha$ - Olefin Copolymer and Grafting of VA onto Copolymer}

The MAA-DA ester with $\alpha$ - olefin $\mathrm{C}_{16}$ (1-Hexadecene) were placed into reaction reactor with suitable amount of benzene with concentration $50 \mathrm{wt} \%$. The reaction was carried out at $80{ }^{\circ} \mathrm{C}$ in the presence of benzoyl peroxide ( $1 \%$ wt $\%$ based on total weight of reactants) as initiator for $6 \mathrm{~h}$. The product was precipitated, filter and drying. Then started to prepared graft copolymer according to the following. The esterified copolymer was blended with $30 \%$ of equivalent weight ratio of vinyl acetate monomer. The mixture was bubbled with nitrogen for $1 \mathrm{~h}$ and the reaction temperature was raised up to $65{ }^{\circ} \mathrm{C}$. Then the initiator benzoyl peroxide (with 0.2 wt $\%$ based on total weight of reactants) was dissolved in benzene with suitable concentration was added to the mixture. The temperature was maintained at the temperature of $65{ }^{\circ} \mathrm{C}$ for $10 \mathrm{~h}$ until the reaction viscosity was increased. 


\section{Petroleum \& Petrochemical Engineering Journal}

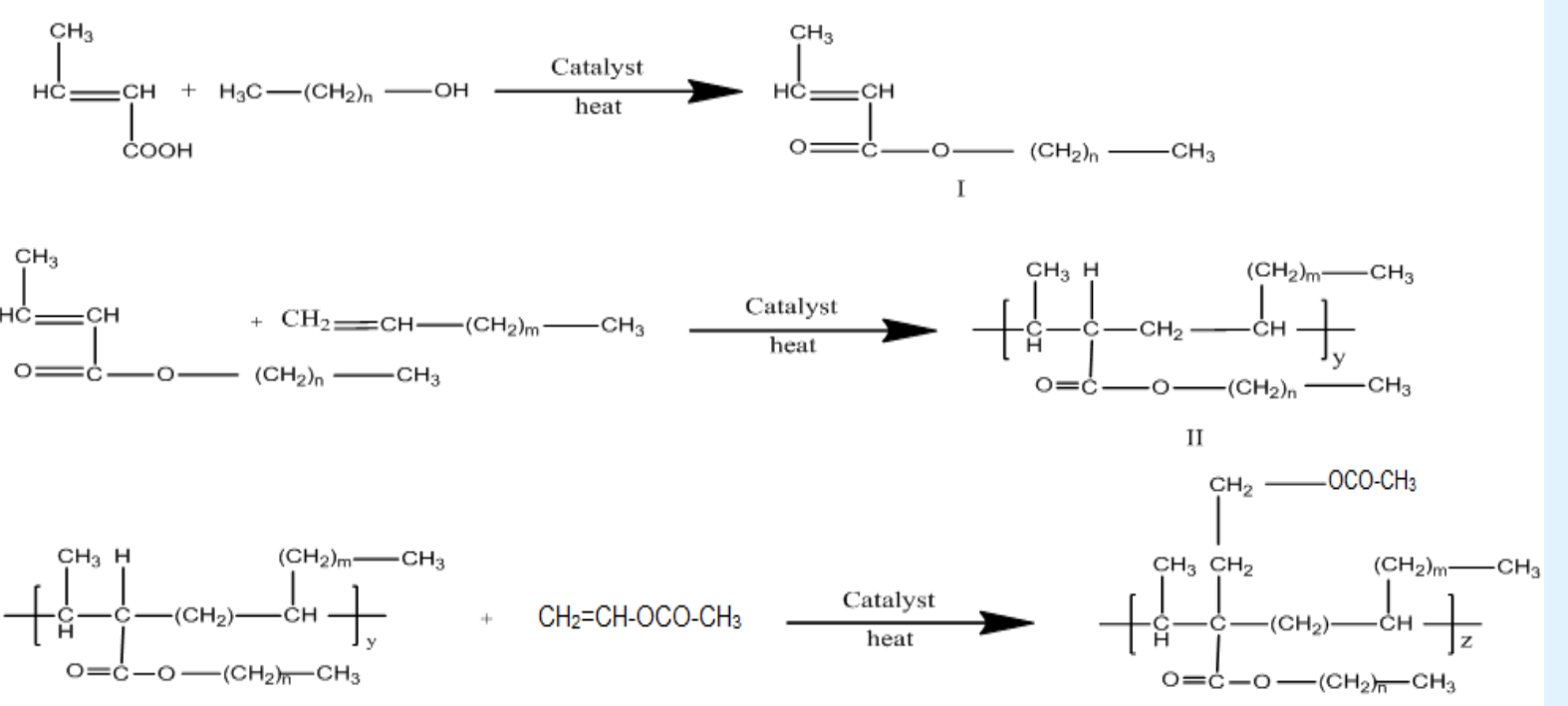

III

Scheme 1: Synthesis of graft co-polymers reaction.

\section{Pour Point Measurement}

The tested lube oils $(50 \mathrm{ml})$ were heated up to $30{ }^{\circ} \mathrm{C}$ and the PPD additive was added at different concentrations. The solution was shacked for 3 minutes and the temperature was kept constant to 5 minutes. The solution was transferred to bottle test tube in water bath cooled at room temperature. The tube was transferred to cooling bath cooled down to $0^{\circ} \mathrm{C}$.

\section{Rheological Measurements}

Rheological measurements test was performed on a Brookfild programmable Rheometer HV DV-III UITRA used in conjunction with Brookfild software, was utilized to measure the dynamic viscosity for untreated and treated lube oils with some selected pour point depressants at different concentrations (from 1000 to $10000 \mathrm{ppm}$ ) at room temperatures. Yield point, and apparent viscosity values were determined.

\section{Determination of Kinematic Viscosity and Viscosity Index}

The kinematic viscosities of the lubricating oils without and with additives were determined, according to ASTM D-445 and ASTM D-446, at $40^{\circ} \mathrm{C}$ and at $100^{\circ} \mathrm{C}$, using a Herzog viscometer. From the obtained kinematic viscosities, the viscosity indexes were calculated, according to ASTM D-2270.

\section{Characterization of the Products}

All reagents and products for reactions performed in this investigation were analyzed by FT-IR in a BIORADExcalibur Series FTS 3500GX system. The method of analysis varied according to the characteristics of the products, however, all of them were performed with 20 scans/min and resolution of $4 \mathrm{~cm}^{-1}$. The copolymer and graft copolymer were analyzed as molten films between $\mathrm{KBr}$ cells. The analyses by hydrogen nuclear magnetic resonance ( $\left.{ }^{1} \mathrm{HNMR}\right)$ were recorded by a BRUKERAdvance 400 (400 MHz) spectrometer operating at $9.4 \mathrm{~T}$, observing hydrogen at $400.13 \mathrm{MHz}$, in detoured chloroform solution (CDC13) and TMS as internal reference to HNMR chemical shifts.

\section{Results \& Discussion}

\section{Characterization of the Prepared Graft Copolymers}

All Prepared Graft Copolymer was soluble in oils and have to be purified before characterization. The purified copolymers were analyzed by FTIR spectroscopy. A spectrum of the purified graft copolymer sample is shown in Figure 1. In this respect, increasing of peak intensity at $1731 \mathrm{~cm}^{-1}$ and decreasing of peak intensity at $1700 \mathrm{~cm}^{-1}$, which represent $\mathrm{C}=\mathrm{O}$ stretching of ester group and carboxylic groups, indicates the conversion of carboxylic 


\section{Petroleum \& Petrochemical Engineering Journal}

acid groups into ester groups. Furthermore, the appearance of strong peak at $1163 \mathrm{~cm}^{-1}$ in all spectra, C-O vibration, indicates the formation of ester graft copolymer. On the other hand, the disappearance of the broad peak at $3450-3100 \mathrm{~cm}^{-1}$ for $(-\mathrm{OH}$ stretching of $\mathrm{COOH}$ group) can be attributed to the formation of ester group for the graft copolymer. To determine the VA contents in copolymers having > 20-40 mol\% VA, the absorption bands at $1370 \mathrm{~cm}^{-1}$ (rocking $\mathrm{CH}_{3}$ in acetate groups) and at $2918 \mathrm{~cm}^{-1}$ (stretching $\mathrm{CH}_{3}$ in ethylene units) were used. In this respect, the chemical structure of graft copolymer can be confirmed by ${ }^{1} \mathrm{HNMR}$ analysis.
The ${ }^{1}$ HNMR spectrum of graft copolymer is presented in Figure 2. The new signals at 2.14, 4.5-4.9 and 3.9 ppm in spectra of graft copolymer, which attributed to $\mathrm{COOCH}_{3}, \mathrm{COOCH}_{2} \mathrm{CH}_{3}$ and $\mathrm{CHCO}$ of VA, indicate that VA was grafted onto copolymer chains. On the other hand, the signals at 1.188 and 1.621 ppm are observed in the spectra and can be attributed to $\mathrm{CH}_{2}$ of ethylene and VA, respectively. The presence of singlet and triplet signals at $0.895,1.156 \mathrm{ppm}\left(\mathrm{CH}_{3}\right)$ in spectra of graft copolymer indicates that $\mathrm{COOH}$ group was esterified with 1-Docanol.
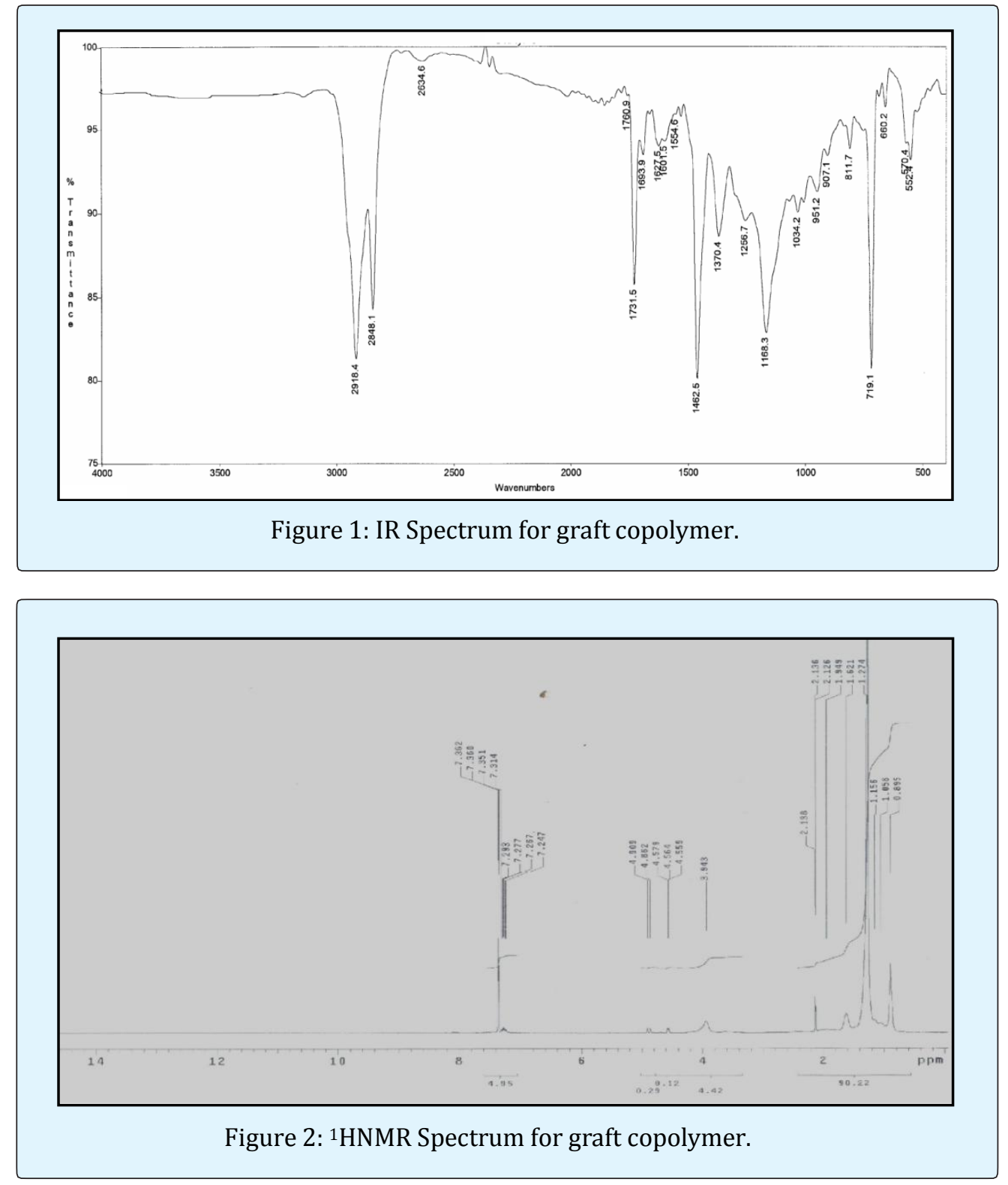


\section{Petroleum \& Petrochemical Engineering Journal}

\section{Physicochemical Properties of Lube Oils}

Table 1 shows the implemented tests and methods for examining the physical and chemical characteristics of lube oils.

\begin{tabular}{|c|c|c|c|}
\hline Test & Lube oil (1) & Lube oil (2) & ASTM methods \\
\hline Viscosity at $40{ }^{\circ} \mathrm{C}$ & 61.52 & 16.18 & D 644 \\
\hline Viscosity at $100{ }^{\circ} \mathrm{C}$ & 8.03 & 3.51 & D644 \\
\hline Viscosity at index & 95 & 90 & D2270 \\
\hline Flash point, ${ }^{\circ} \mathrm{C}$ & 239 & 200 & D 93, D94 \\
\hline Pour point, ${ }^{\circ} \mathrm{C}$ & 0.0 & 3.0 & D97 \\
\hline Apparent viscosity, $\mathrm{cP}$ at $40{ }^{\circ} \mathrm{C}$ & 66.5 & 19.8 & \\
\hline
\end{tabular}

Table 1: Physicochemical characteristics of treated lube oils.

\section{Pour point}

The pour point results and pour point reduction $(\Delta \mathrm{P})$ for pure lube oils and for the lube oils containing additive are shown in Table 2.

The date in Tables 2 , show the lube oils which have PPD are exhibiting a lower pour point more than that without PPD at different doses ranging from 1000 to $10000 \mathrm{ppm}$. The effectiveness of a pour point depressant depends on the chemical composition and structural characteristics of the polymer and the length of the alkyl side chain $[16,17]$.

Cold flow properties of the prepared sample were determined using their pour points temperatures. In practice, the usable liquid range is limited by the pour point (PP) at low temperatures. The data in Table 2 illustrate the PPT decrease by increasing concentrations up to $1 \%$ of PPD. The PP should be low to ensure that the lubricant is pump able when the equipment is started from extremely low temperatures [18].

\begin{tabular}{|c|c|c|c|c|c|c|c|}
\hline \multirow{2}{*}{ Lube oil (1) } & \multirow{2}{*}{ Dose, ppm } & \multicolumn{2}{|c|}{ PPT } & \multirow{2}{*}{ Lube oil (2) } & \multirow{2}{*}{ Dose, ppm } & \multicolumn{2}{|c|}{ PPT } \\
\hline & & $\mathrm{PP},{ }^{\circ} \mathrm{C}$ & $\Delta \mathbf{P}$ & & & $\mathrm{PP},{ }^{\circ} \mathrm{C}$ & $\Delta \mathbf{P}$ \\
\hline \multirow{6}{*}{ 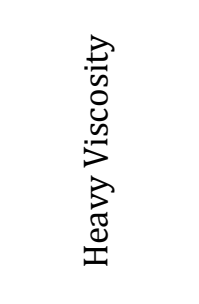 } & Blank & 0.0 & 0.0 & \multirow{6}{*}{ 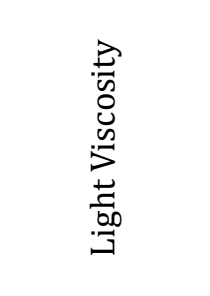 } & Blank & 3.0 & 0.0 \\
\hline & 1000 & -9 & 9 & & 1000 & -6 & 9 \\
\hline & 2000 & -12 & 12 & & 2000 & -9 & 12 \\
\hline & 3000 & -15 & 15 & & 3000 & -12 & 15 \\
\hline & 5000 & -18 & 18 & & 5000 & -15 & 18 \\
\hline & 10000 & -18 & 18 & & 10000 & -15 & 18 \\
\hline
\end{tabular}

Table 2: Pour point data of untreated and treated heavy and light lubricating oils with graft copolymer concentrations.

\section{Effect of Additives on Rheology of Lube Oils}

The flow properties of lube oils depend strongly on the shear rate, temperature, rate of cooling, time of shearing, and composition of the crude oil [6].

Hence, copolymer additives were evaluated for their performance as flow improvers in the two tested lube oils through rheological measurements at concentration of 1000-10000 ppm. Measurements of the shear stress- shear rate and viscosity- shear rate relationships were carried out at temperature $25 \stackrel{\circ}{\circ} \mathrm{C}$. Viscosity - shear rate and shear stress - shear rate relationships for the untreated and treated lube oils with additive at different concentrations and temperature $25 \stackrel{\circ}{\circ} \mathrm{C}$ were plotted in Figures 3-6. This figure illustrates the fitted experimental data of both shear stress and shear rate measurements according to the Bingham plastic model. 


\section{Petroleum \& Petrochemical Engineering Journal}

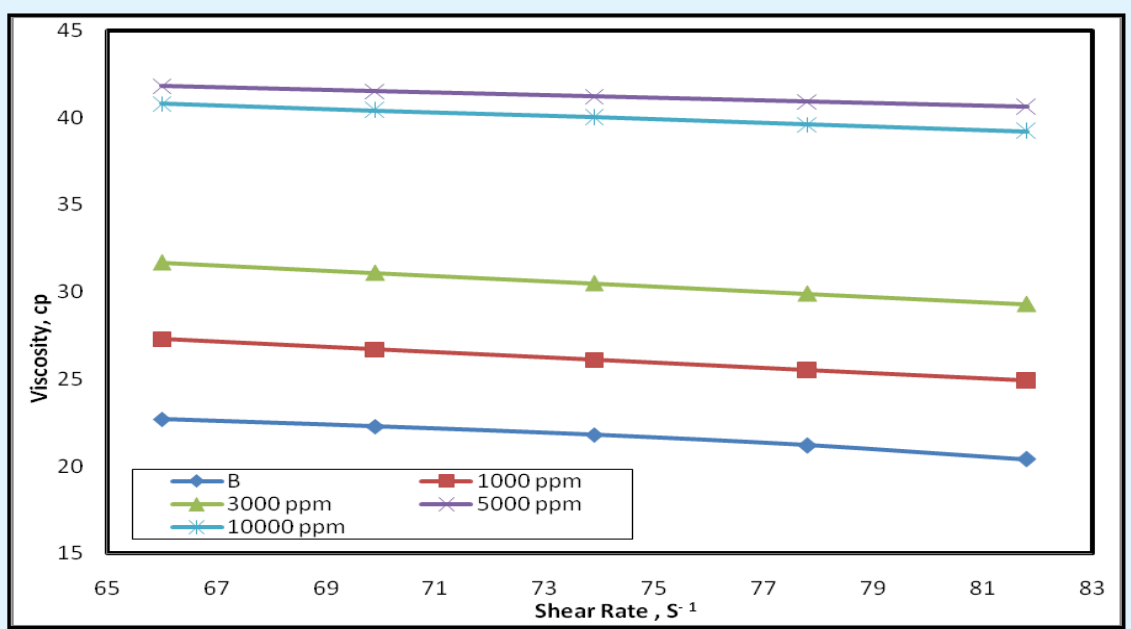

Figure 3: Relationship between shear rate and viscosity of light lubricating oil with different concentrations from graft co-polymer at $25^{\circ} \mathrm{C}$.

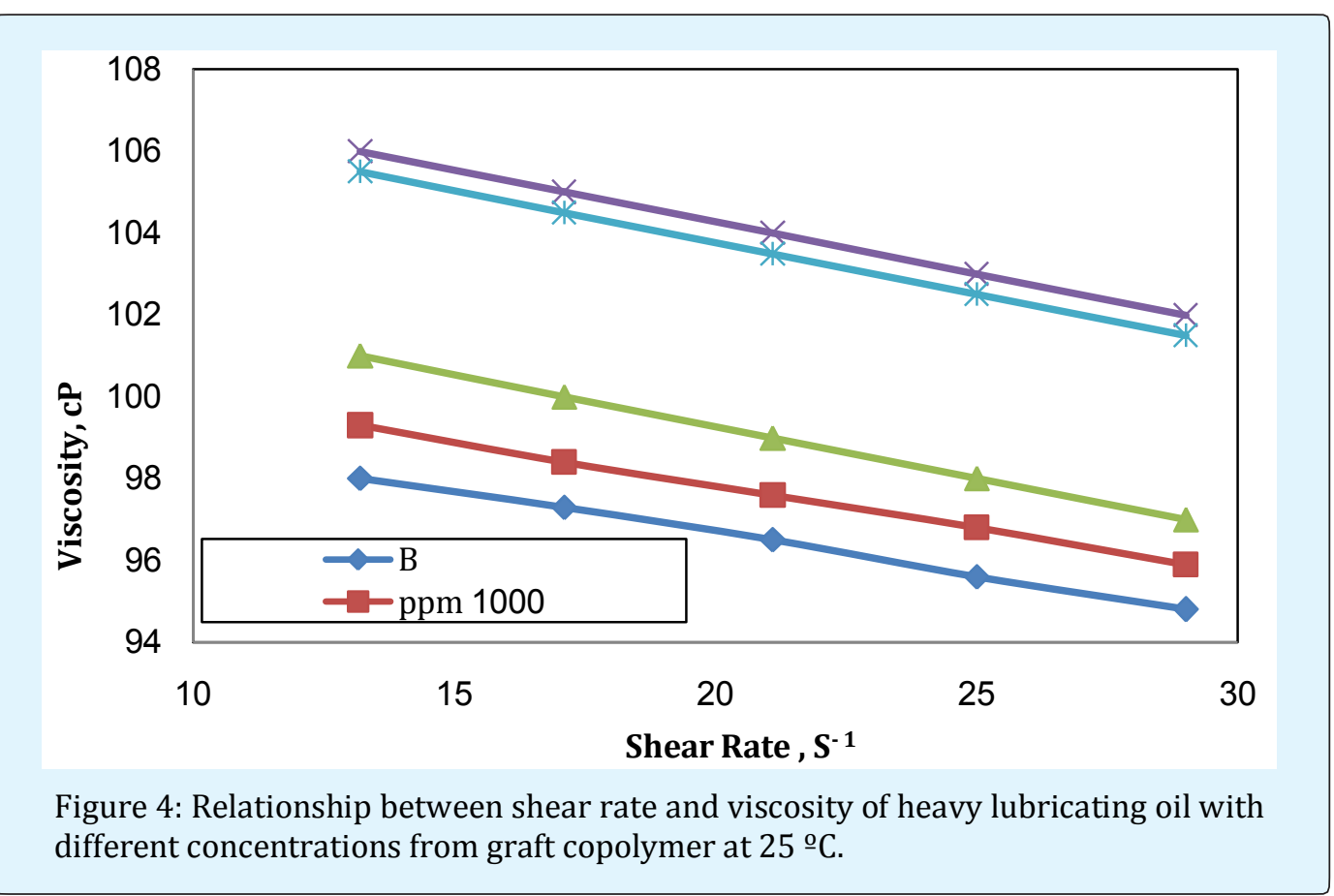

Figures 3-6 illustrate behavior of lube oils were increasing the rheological parameters after addition of the prepared graft copolymers (until $5000 \mathrm{ppm}$ ) can thus be attributed to their chemical structure of additive. The high polarity of oxygen in the ester group along the copolymer chain was playing a role in preventing the agglomeration of wax crystals in lube oils [19]. In addition, the interaction of the alkyl branch with the paraffin fraction in the oils occur through well matching of the alkyl chain length and as discussed before, as the alkyl chain length increases a better mach occurs [20].

However, the dynamic viscosity decreases with increasing the shear rate reaching a limiting value at high shear rate. This infinite shear rate viscosity is known as the apparent viscosity [21]. This behavior may be explained by increasing the shear rate, the size of the agglomerates decreases and this process releases some of 


\section{Petroleum \& Petrochemical Engineering Journal}

the continuous phase originally immobilized within the agglomerates. The viscosity decreases with increasing the shear rate until the agglomerates are completely broken into the basic particles. So the lube oils system shows nonNewtonian characteristic [22].
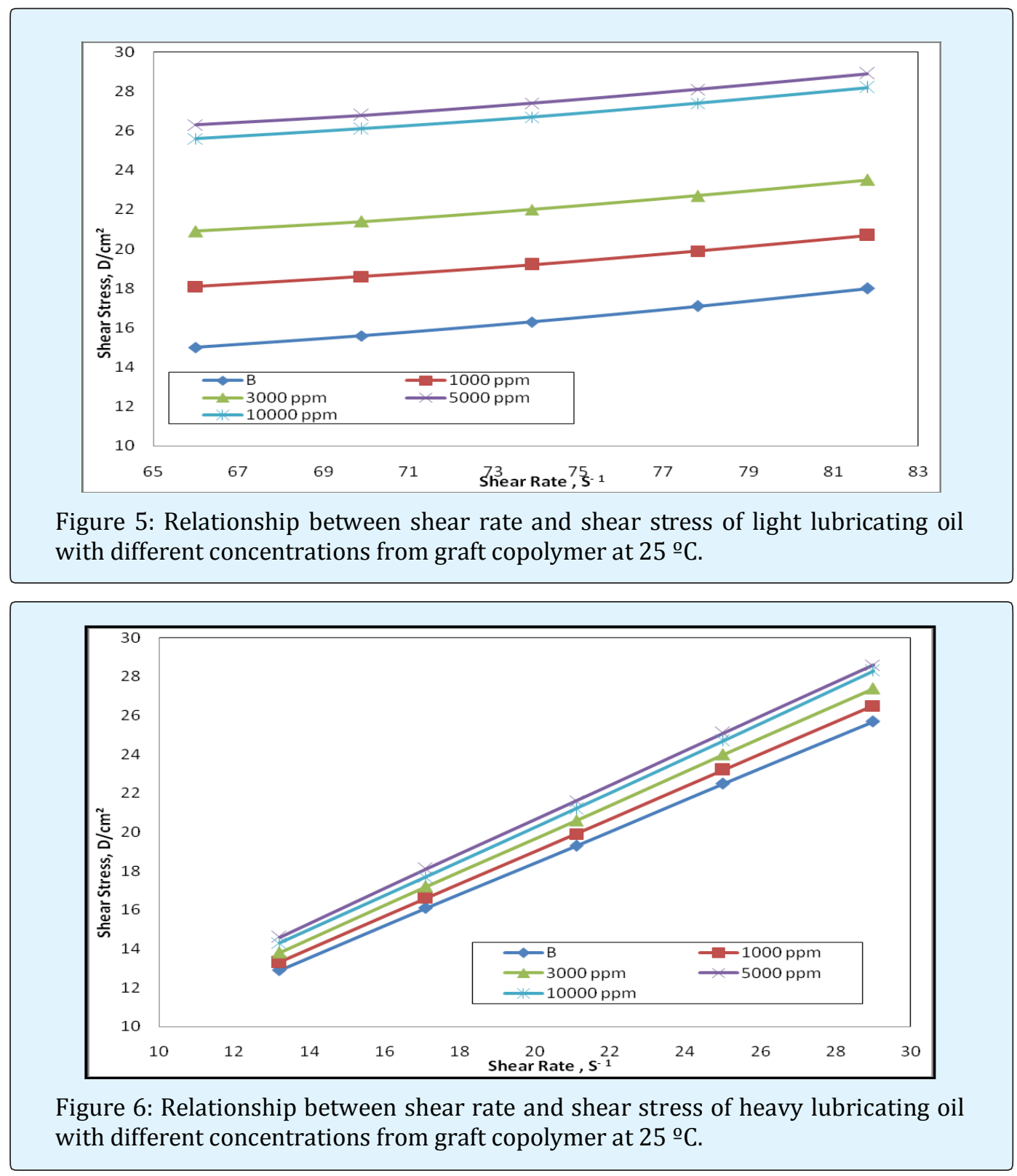

\section{Determination of Kinematic Viscosity and Viscosity Index}

The viscosity index, commonly designated VI, is an arbitrary numbering scale that indicates the changes in oil viscosity with changes in temperature. A low index means a steep slope of the curve, or a great variation of viscosity with a change in temperature; high index means a flatter slope, or lesser variation of viscosity with the same changes in temperature. Increased viscosity index (VI) of lubricating oils with graft copolymer additive is the result of its higher molar weight, and especially the structure of additive molecules. In this respect, the data in Table 3 show the VI values are high, characteristic for lubricating oils. As seen, from the results presented in Table 3, the kinematic viscosities of lube oils, at both temperatures which is in accordance with the specifications for these 


\section{Petroleum \& Petrochemical Engineering Journal}

products [8]. At both temperatures, the kinematic viscosities of the mixtures (oils with additives) are higher than those of pure oils, and they increase with increasing concentrations [23]. From the results obtained in the present work, it can be observed that both oils (Light oil and Heavy oil) with additive are shown a good result.

\begin{tabular}{|c|c|c|c|c|c|c|c|}
\hline \multirow{2}{*}{ Heavy Oil } & \multicolumn{2}{|c|}{ Kinematic Viscosity } & \multirow{2}{*}{ Viscosity Index } & \multirow{2}{*}{ Light Oil } & \multicolumn{2}{|c|}{ Kinematic Viscosity } & \multirow{2}{*}{ Viscosity Index } \\
\cline { 2 - 3 } & $\mathbf{@} \mathbf{4 0} \mathbf{C}$ & $@ \mathbf{1 0 0}^{\circ} \mathbf{C}$ & & & $40^{\circ} \mathrm{C}$ & @ $100^{\circ} \mathrm{C}$ & \multirow{2}{*}{} \\
\hline Blank & 61.52 & 8.03 & 95 & Blank & 16.18 & 3.51 & 90 \\
\hline $1000 \mathrm{ppm}$ & 62.42 & 8.21 & 98 & $1000 \mathrm{ppm}$ & 16.27 & 3.67 & 110 \\
\hline $3000 \mathrm{ppm}$ & 64.15 & 8.73 & 108 & $3000 \mathrm{ppm}$ & 16.43 & 3.86 & 130 \\
\hline $5000 \mathrm{ppm}$ & 65.86 & 9.25 & 117 & $5000 \mathrm{ppm}$ & 17.11 & 4.05 & 138 \\
\hline $10000 \mathrm{ppm}$ & 67.48 & 9.69 & 124 & $10000 \mathrm{ppm}$ & 19.21 & 4.73 & 176 \\
\hline
\end{tabular}

Table 3: The effect of different concentration of additives on kinematic viscosity and viscosity index for light lubricating oil.

\section{Conclusion}

1. In using the polymer additives obtained in this investigation, a reduction in the pour point of a sample of lube oils, thus demonstrating the efficiency of the products synthesized in this study.

2. For light and heavy lubricating oils, the best performance as pour point depressant was obtained with 5000 ppm from graft co-polymer.

3 . The prepared materials show good results as Viscosity index at $10000 \mathrm{ppm}$ for light and heavy lube oils.

4. The data of rheological measurements indicate that the viscometric behaviors of the treated lubricating oils depend on the compatibility between lube oils compositions and the structure of the prepared graft copolymeric additives.

5. There is an apparent disagreement between the pour point reduction and the rheological results obtained for the graft copolymer. This difference has been ascribed to the different wax particles behavior in the static pour point test and in the measurements involving shearing.

\section{References}

1. Ghosh P and Das T (2014) Synthesis and Characterization of Homopolymer of Decyl Acrylate and its Copolymer with Styrene and Evaluation of their Performance as a Pour Point Depressant in Lubricating Oil. Petroleum Science and Technology 32(12): 1448-1457.

2. Covitch MJ (2009) Olefin Copolymer Viscosity Modifiers. In: Rudnick LR (Ed), Lubricant Additives. $2^{\text {nd }}($ Edn.), CRC Press, Boca Raton, pp: 283-314.
3. Kinker BG (2009) Polymethacrylate Viscosity Modifiers and Pour Point Depressants. In: Rudnick LR (Ed), Lubricant Additives. $2^{\text {nd }}$ (Edn.), CRC Press, Boca Raton, pp: 315-337.

4. El-Adly RA, Ismail EA (2011) Lubricating Greases Based on Fatty By-Products and Jojoba Constituents, In: Kuo $\mathrm{CH}$ (Ed), Tribology - Lubricants and Lubrication. Chap(8), pp: 1-23.

5. Pranab Ghosh and Moumita Das (2013) Synthesis, Characterization, and Performance Evaluation of Some Multifunctional Lube Oil Additives. J Chem Eng Data 58(3): 510-516.

6. Delpech MC, Coutinho FMB, Habibe MES (2002) Viscometry Study of Ethylene-Cyclic Olefin Copolymers. Polym Test 21(4): 411-415.

7. Al-Shafey HI, Hashem AI, Abdel Hameed RS, Dawood EA (2011) Studies on the Influence of Long Chain Acrylic Esters Co-Polymers Grafted With Vinyl Acetate as Flow Improver Additives of Crude Oils. Advances in Applied Science Research 2(5): 476-489.

8. Ahmed NS, Nassar AM, Nasser RM, Khattab AF and Abdel-Azim, AAA (2008) Synthesis and Evaluation of Some Polymeric Compounds as Pour Point Depressants and Viscosity Index Improvers for Lube Oil. Petrol Sci Technol 26(12): 1390-1402.

9. Al-Shafy HI, Ismail EA (2014) Studies on the Influence of Polymeric Additives as Flow Improvers for Waxy Crude Oil. International Organization of Scientific Research 4(7): 54-61. 


\section{Petroleum \& Petrochemical Engineering Journal}

10. Atta AM, Al-Shafey HI, Ismail EA (2011) Influence of Ethylene Acrylic Alkyl Ester Copolymer Wax Dispersants on the Rheological Behavior of Egyptian Crude Oil. J Dispersion Science Technology 32: 12961305.

11. Andre LCM, Elizabete FL (2002) Influence of Ethylene Co-vinyl Acetate Copolymers on the Flow Properties of Wax Synthetic Systems. J Appl Polym Sci 85: 13371348.

12. Anwar M, Khan H, Nautiyal S, Agrawal K, Rawat B (1999) Solubilised Waxes and Their Influence on the Flow Properties of Lube Oil Base Stocks. Petrol Sci Technol 17(5-6): 491-501.

13. Nassar AM (2008) The Behavior of Polymers as Viscosity Index Improvers. Petrol Sci Technol 26(5): 514-522.

14. Mohamed MM, Naga HHAEL, Meneir MFEL (1994) Multifunctional Viscosity Index Improvers, J Chem Technol Biotechnol 60(3): 283-289.

15. Covitch MJ, Trickett KJ (2015) How Polymers Behave as Viscosity Index Improvers in Lubricating Oils. Advances in Chemical Engineering and Science 5(2): 134-151.

16. Jung KM, Chun BH, Park SH, Lee CH, Kim SH (2011) Synthesis of Methacrylate Copolymers and Their Effects as Pour Point Depressants for Lubricant Oil. J Appl Polym Sci 120(5): 2579-2586.

17. Ghosh P, Das T, Nandi D, Karmakar G, Mandal A (2010) Synthesis and Characterization of
Biodegradable Polymer-Used as a Pour Point Depressant for Lubricating Oil. Int J Polym Mater 59(12): 1008-1017.

18. Du T, Wang S, Liu H, Song C, Nie Y (2012) The Synthesis and Characterization of Methacrylic Acid Ester-Maleic Anhydride Copolymer as a Lube Oil Pour Point Depressant. Petrol. Sci. Technol 30(2): 212-221.

19. Mello IL, Delpech MC, Coutinho FMB, Albino FFM (2006) Viscometric Study of High-Cis polybutadiene in Toluene Solution. J Braz Chem Soc 17(1): 194-199.

20. AL-Shafey HI (2007) Ph.D. Thesis, Synthesis of some polemeric derivatives based on Colophony to solve the trans portation problem of som Egyptian Waxy Crude oils. AL-Azhar University, Cairo, Egypt.

21. Ghosh P, Das T, Nandi D (2009) Synthesis of Copolymers and Homopolymers of Methyl Methacrylate and Styrene and Studies on their Viscometric Properties in Three Different Solvents. Res J Chem Environ 13(1): 17-25.

22. Ghosh P, Das T, Das M (2011) Evaluation of Poly(acrylates) and Their Copolymer as Viscosity Modifiers. Res J Chem Sci 1(3): 18-25.

23. Ghosh P, Das T, Karmakar G, and Das M (2011) Evaluation of Acrylate-Sunflower Oil Copolymer as Viscosity Index Improvers for Lube Oils. J Chem Pharm Res 3(3): 547-556. 